University of New Hampshire

University of New Hampshire Scholars' Repository

Physics Scholarship

Physics

7-15-2015

\title{
Extreme geomagnetic disturbances due to shocks within CMEs
}

Noe E. Lugaz

University of New Hampshire - Main Campus, Noe.Lugaz@unh.edu

Charles J. Farrugia

University of New Hampshire - Main Campus, Charlie.Farrugia@unh.edu

Chia-Lin L. Huang

University of New Hampshire - Main Campus, hcl@guero.sr.unh.edu

Harlan E. Spence

University of New Hampshire, harlan.spence@unh.edu

Follow this and additional works at: https://scholars.unh.edu/physics_facpub

Part of the Astrophysics and Astronomy Commons

\section{Recommended Citation}

Lugaz, N., C. J. Farrugia, C.-L. Huang, and H. E. Spence (2015), Extreme geomagnetic disturbances due to shocks within CMEs. Geophys. Res. Lett., 42, 4694-4701. doi: 10.1002/2015GL064530.

This Article is brought to you for free and open access by the Physics at University of New Hampshire Scholars' Repository. It has been accepted for inclusion in Physics Scholarship by an authorized administrator of University of New Hampshire Scholars' Repository. For more information, please contact Scholarly.Communication@unh.edu. 


\section{Geophysical Research Letters}

\author{
RESEARCH LETTER \\ 10.1002/2015GL064530 \\ Key Points: \\ - Shocks inside CME have simultaneous \\ dynamic pressure and $\mathrm{Bz}$ increases \\ - Shocks inside CMEs can cause \\ magnetopause shadowing \\ - Extreme solar wind-magnetosphere \\ coupling for weak drivers
}

Correspondence to:

N. Lugaz,

noe.lugaz@unh.edu

\section{Citation:}

Lugaz, N., C. J. Farrugia, C.-L. Huang, and H. E. Spence (2015), Extreme geomagnetic disturbances due to shocks within CMEs, Geophys. Res. Lett., 42, 4694-4701, doi:10.1002/2015GL064530.

Received 11 MAY 2015 Accepted 20 MAY 2015 Accepted article online 27 MAY 2015 Published online 19 Jun 2015

\section{Extreme geomagnetic disturbances due to shocks within CMEs}

\author{
N. Lugaz ${ }^{1}$, C. J. Farrugia ${ }^{1}$, C.-L. Huang ${ }^{1}$, and H. E. Spence ${ }^{1}$ \\ ${ }^{1}$ Department of Physics and Space Science Center, University of New Hampshire, Durham, New Hampshire, USA
}

\begin{abstract}
We report on features of solar wind-magnetosphere coupling elicited by shocks propagating through coronal mass ejections (CMEs) by analyzing the intense geomagnetic storm of 6 August 1998 . During this event, the dynamic pressure enhancement at the shock combined with a simultaneous increase in the southward component of the magnetic field resulted in a large earthward retreat of Earth's magnetopause, which remained close to geosynchronous orbit for more than $4 \mathrm{~h}$. This occurred despite the fact that both shock and CME were weak and relatively slow. Another similar example of a weak shock inside a slow CME resulting in an intense geomagnetic storm is the 30 September 2012 event, which strongly depleted the outer radiation belt. We discuss the potential of shocks inside CMEs to cause large geomagnetic effects at Earth, including magnetopause shadowing.
\end{abstract}

\section{Introduction}

So far, research on the geomagnetic effects of solar wind structures [e.g., see Borovsky and Denton, 2006] has typically distinguished between coronal mass ejections (CMEs) and corotating interaction regions (CIRs). The former are associated with strong disturbances, whereas the latter usually give rise to moderate storms [Gosling et al., 1991; Richardson et al., 2001; Zhang et al., 2007]. Both interplanetary (IP) shocks and CIRs result in a large solar wind dynamic pressure increase, which compresses the magnetopause and may significantly affect the magnetospheric current systems. Magnetic ejecta inside CMEs, on the other hand, primarily affect the Earth's magnetosphere through magnetic reconnection during a period of intense and prolonged southward $B_{z}$. Fast CMEs drive shocks, and the shock plus ejecta may result in a two-stage geomagnetic disturbance [Kamide et al., 1998].

Here we present a new cause for intense geomagnetic storms: an IP shock propagating within a CME. Wang et al. [2003] looked at the geomagnetic response of a shocked CME, but they did not discuss the details of the solar wind-magnetosphere coupling. In a recent paper [Lugaz et al., 2015], we examined all cases of a fast-forward shock propagating through a CME during solar cycle 23, finding 49 such occurrences. In 19 cases, there was an intense geomagnetic storm within $12 \mathrm{~h}$ of shock impact. This shows that such shocks are frequent and that they can strongly disturb the magnetosphere.

In this letter, we report on the intense main phase of a geomagnetic storm on 6 August 1998 which took place during a $5 \mathrm{~h}$ period following the passage at Wind of a shock inside a CME. In section 2, we discuss the solar wind and magnetosheath measurements during this shock passage, with emphasis on the changes in the bow shock and magnetopause due to the shock and shocked CME material. In section 3, we analyze the geomagnetic response to this event. We then compare it with the 30 September 2012 event in section 4, and we draw our conclusions in section 5 .

\section{The 6 August 1998 Event: IP and Magnetosheath Measurements}

\subsection{IP Measurements}

A CME passed over the Wind spacecraft from 5 August 13:00 UT to 6 August 12:30 UT [Richardson and Cane, 2010]. With a speed of $360 \mathrm{~km} \mathrm{~s}^{-1}$, it was a slow CME which did not drive a shock. However, it had relatively clear signatures, especially starting around 02:00 UT, 6 August, with an enhanced interplanetary magnetic field (IMF) strength of 9-10 nT, a southward (GSM) magnetic field $B_{z} \sim-7 \mathrm{nT}$, low proton temperature, and $\beta$. The CME ended at 12:30 UT, as identified by a quick change of the IMF clock angle to northward $B_{z}$, higher level of turbulence, and higher proton $\beta$.

At 07:16 UT, $5 \mathrm{~h}$ before the CME encounter ended, Wind observed the passage of an IP shock. This shock was likely to have been driven by the overtaking CIR, as identified by Jian et al. [2006]. The shock speed in the rest
@2015. American Geophysical Union. All Rights Reserved. 


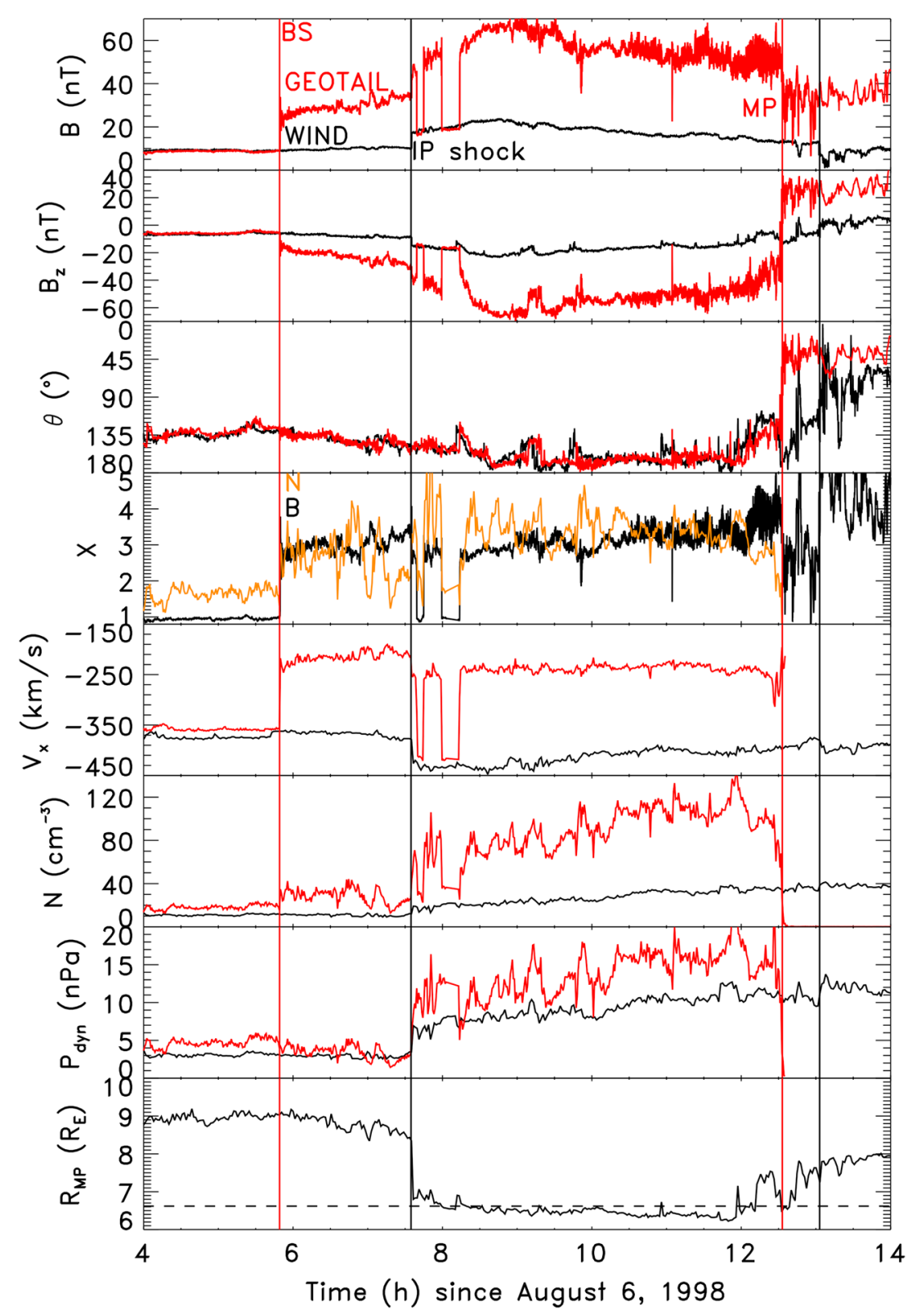

Figure 1. Comparison of magnetosheath (Geotail, red) and IP (Wind, black) measurements; (first panel) the magnetic field strength, (second panel) the magnetic field GSM $B_{z}$ component; (third panel) clock angle, $\theta$; (fourth panel) the compression, $X$, in magnetic field (black) and density; (fifth panel) the radial speed; (sixth panel) proton density; (seventh panel) dynamic pressure; and (eighth panel) the location of the subsolar magnetopause using the Shue et al. [1998] model. The red vertical lines mark the location of the bow shock (BS) and magnetopause (MP) crossing by Geotail. The black vertical lines mark the position of the shock and the end of the CME.

frame was about $480 \mathrm{~km} \mathrm{~s}^{-1}\left(110 \mathrm{~km} \mathrm{~s}^{-1}\right.$ in the solar wind frame), and it compressed the density and magnetic field by a factor of $\sim 1.8$. This was a weak $\left(M_{\mathrm{ms}} \sim 1.6\right)$ and quasi-perpendicular shock (angle with the IMF of $85^{\circ}$ ). The final $5 \mathrm{~h}$ of the CME were clearly strongly affected by the shock passage: the IMF and density were, respectively, 1.5-2.5 and 2-4 times stronger than before the shock. The stream interface of the CIR occurred immediately after the CME end.

\subsection{Magnetosheath Measurements and Bow Shock Crossings}

On 6 August, Geotail was inbound in the afternoon and dusk sectors of the magnetosheath, following a low-inclination orbit starting at $(13,17,-1) R_{E}$ at 00:00 UT to $(-0.5,12,-5) R_{E}$ at 12:00 UT (GSM coordinates). Geotail crossed the bow shock into the magnetosheath at 05:49 UT (first red vertical guideline of Figure 1) before the arrival of the IP shock. Based on typical bow shock shapes, this implies that the bow shock nose 
was at around $13 \mathrm{R}_{E}$, or slightly more earthward than typical. This is consistent with the IP measurements at that time, which showed a southward $B_{z}$ component of about $-7 \mathrm{nT}$.

A fast-forward shock was detected at Geotail at 07:35 UT. Figure 1 compares the IP (black) and magnetosheath (red) measurements, time shifted to the arrival of the IP shock. The compression in magnetic field strength through the shock was only about 1.25, significantly less than the compression of the shock in the IP medium. This shock was the counterpart in the magnetosheath of the IP shock detected $0.45 \mathrm{~h}$ earlier at Wind. It was weaker due to its interaction with Earth's bow shock, consistent with previous studies [Grib et al., 1979; Samsonov et al., 2006]. According to these studies, the density rise at the IP shock should be distributed over two components (a shock and a discontinuity) following the interaction with the bow shock, hence the lower compression ratio seen at the shock by Geotail. Following the fast-mode forward shock, Geotail experienced a series of bow shock crossings with the last one occurring at 08:15 UT. Through each of these crossings, Geotail measured a compression in the magnetic field by a factor of about 2.7 or nearly identical to the bow shock compression measured before the arrival of the IP shock. The combined effect of the bow shock and IP shock resulted in extreme values of the magnetic field and density in the magnetosheath. Particularly noteworthy in Figure 1 are (i) the strong southward field in the magnetosheath, reaching $-70 \mathrm{nT}$; (ii) the large densities there, up to $110 \mathrm{~cm}^{-3}$; and (iii) the low position of the subsolar magnetopause (Figure 1, eighth panel; see further below).

\subsection{Magnetopause Shape and Location}

We calculated the expected location of the magnetopause (Figure 1, eighth panel) and its shape using the model by Shue et al. [1998], which is applicable to extreme interplanetary conditions (extreme values of the model inputs: $B_{z}$ and $P_{\text {dyn }}$ ). Before the arrival of the IP shock, the distance from the Earth to the subsolar point of the magnetopause was $9 R_{E}$. The arrival of the shock pushed the magnetopause standoff distance by $2.5 \mathrm{R}_{E}$, down to geosynchronous orbit. Including the erosion term associated with the effects of $B_{z}$ is essential, since it eroded the dayside magnetopause by $1.5 \mathrm{R}_{E}$ further than without including it. The magnetopause then remained around the location of geosynchronous orbit for $\sim 5 \mathrm{~h}$. During this time period, its aspect ratio became large (i.e., the magnetopause "flared" out) with values of up to 1.7 instead of 1.55 before shock passage (not shown).

The first bow shock crossing by Geotail occurred before the arrival of the IP shock at 05:49 UT, a time when Geotail was at $(6.65,15.9,-4.12) R_{E}$ in GSM coordinates. After the IP shock, Geotail crossed the bow shock twice more in each direction, the last crossing occurring at 08:13 UT, when Geotail was at $(4.0,14.9,-5.26) R_{E}$. During this interval, the solar wind magnetosonic Mach number was slowly decreasing from 5.1 to 4.3 . This decrease is expected to increase the bow shock standoff distance, so the measured earthward motion of the bow shock must reflect an earthward motion of the magnetopause, by about $2.5 R_{E}$. This is consistent with the results from the formula by Shue et al. [1998], which predict an earthward motion by $2.4 R_{E}$ of the nose of the magnetopause and a motion by about 3-3.5 $R_{E}$ of the flank of the magnetosphere.

Geotail crossed the magnetopause into the magnetosphere at 12:33 UT, when the spacecraft was at $(-1.02$, $12.6,-4.63) R_{E}$. This crossing occurred slightly earlier than expected based on the formula by Shue et al. [1998], although it should be noted that the magnetopause started to move significantly due to large changes in the solar wind around 12:10 UT. The clock angle changed by over $90^{\circ}$ at the magnetopause, producing conditions favorable for dayside reconnection. In addition, the magnetic pressure was larger in the magnetosphere than in the magnetosheath, which is highly unusual but has been discussed by Panov et al. [2008]. In fact, the transition was from a low- $\beta$ magnetosheath to a high- $\beta$ magnetosphere. The fact that the magnetosheath has a low $\beta$ is somewhat expected due to the relatively low Alfvén Mach number of the solar wind, as discussed in Farrugia et al. [1995] and Lavraud and Borovsky [2008]. However, this occurred in a period of high densities and dynamic pressure, not low densities as is typical of a CME passage. The high- $\beta$ magnetosphere was probably due to the influence of ring current particles in the pressure balance.

\section{Effects of the Shock and Shocked CME on Earth's Magnetosphere}

Figure 2 shows the geomagnetic indices during the period of interest. Before the arrival of the IP shock in the weak CME, the coupling electric field following Kan and Lee [1979] was between 3 and $3.5 \mathrm{mV} \mathrm{m}^{-1}$, corresponding to a weak driving of the magnetosphere through reconnection. The SYM- $H$ index was about $-20 \mathrm{nT}$, and there was one substorm onset during the $6 \mathrm{~h}$ preceding the shock arrival with a drop of the $A L$ index to $-700 \mathrm{nT}$ concomitant with an increase of the polar cap north index to $4 \mathrm{mV} \mathrm{m}^{-1}$ at 04:00 UT. 

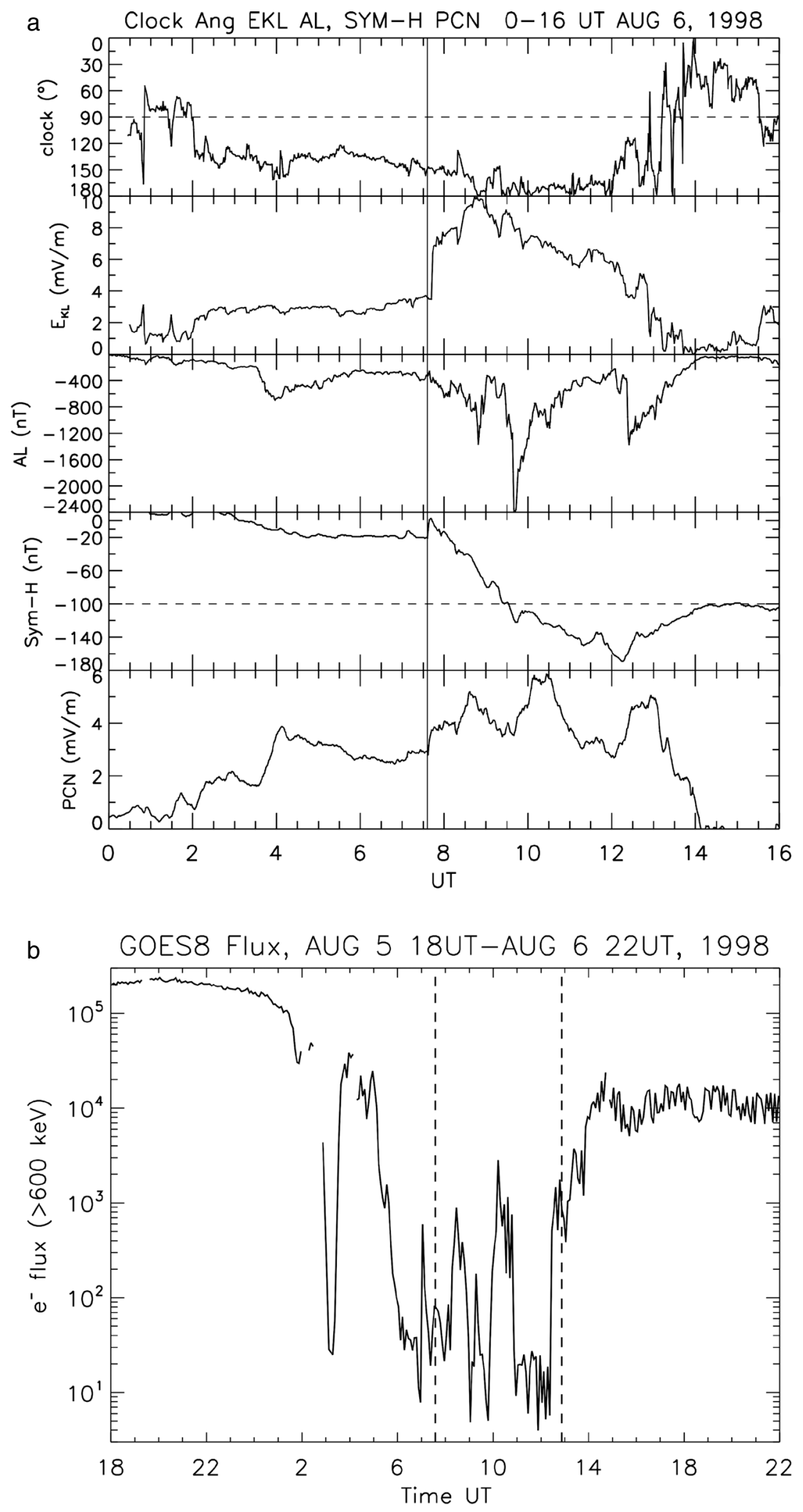

Figure 2. Geomagnetic indices, with important IP parameters included for reference. (a) From top to bottom, the IMF clock angle, the merging electric field, the auroral $A L$ electrojet index, the SYM-H index, and the polar cap north index, PCN. (b) The flux of energetic electrons (above $600 \mathrm{keV}$ ) measured by GOES 8 at geosynchronous orbit over a $28 \mathrm{~h}$ time period centered around the time of shock arrival (first vertical line) and end of CME (second vertical line). 


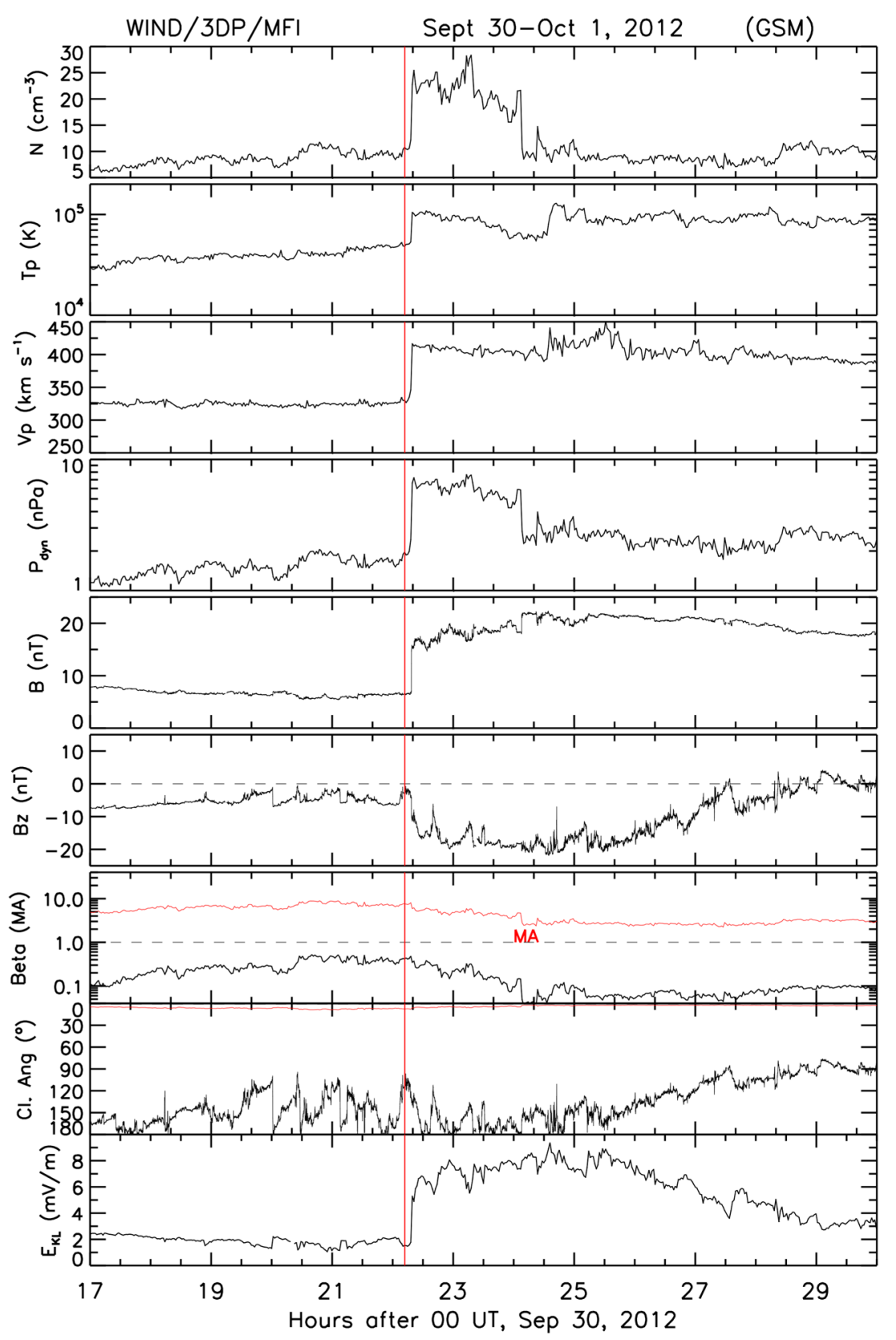

Figure 3. Wind measurements on 30 September to 1 October 2012 showing (first panel) proton density, (second panel) temperature, (third panel) velocity, (fourth panel) the dynamic pressure, (fifth panel) magnetic field strength, (sixth panel) $B_{Z}$ (GSM) component, (seventh panel) the proton $\beta$ (Alfvén Mach number in red), (eighth panel) magnetic field clock angle, and (ninth panel) Kan-Lee electric field. The shock is marked with the red vertical line.

Large effects were seen in the $5 \mathrm{~h}$ following the shock passage. $E_{\mathrm{KL}}$ reached values of $10 \mathrm{mV} \mathrm{m}^{-1}$, and the dynamic pressure reached values above $10 \mathrm{nPa}$. After a sudden impulse, the $S Y M-H$ index quickly decreased to $-122 \mathrm{nT}$ at 09:42 UT, i.e., about $2 \mathrm{~h}$ after the shock arrival at Geotail. The geomagnetic storm further intensified with a slower decrease of SYM-H to a minimum of $-178 \mathrm{nT}$ at 12:20 UT. Recovery started at the end of the interval, when the IMF turned northward and CME passage ended. The $A L$ index showed three substorm onsets, in the second of which it went to extreme values of $-2400 \mathrm{nT}$. Overall, these effects were by far the largest observed in the $48 \mathrm{~h}$ period of this combined CME and CIR passage at Earth.

The PCN index showed evidence of strong convection. Under "normal" conditions, the magnitude of the driving electric field $\left(\sim 10 \mathrm{mV} \mathrm{m}^{-1}\right)$ would typically result in saturation of the cross-polar cap potential (CPCP) 
Table 1. Comparison of the CME, Shock, and IP Conditions for the 6 August 1998 and 30 September 2012 Events $^{\mathrm{a}}$

\begin{tabular}{|c|c|c|c|c|c|c|}
\hline Date & Dt & Type & $B_{\max }$ & $B_{z}$ & $V$ & $N$ \\
\hline & \multicolumn{6}{|c|}{$C M E$} \\
\hline 08/98 & $24 \mathrm{~h}$ & NES & $10.5 \mathrm{nT}$ & $-9 \mathrm{nT}$ & $360 \mathrm{~km} / \mathrm{s}$ & $11 \mathrm{~cm}^{-3}$ \\
\hline \multirow[t]{3}{*}{$09 / 12$} & $12 \mathrm{~h}$ & WSE & $8.3 \mathrm{nT}$ & $-8 \mathrm{nT}$ & $315 \mathrm{~km} / \mathrm{s}$ & $10 \mathrm{~cm}^{-3}$ \\
\hline & $\Delta t$ & $V$ & $x_{N}$ & $X_{B}$ & $\Theta$ & $M_{\mathrm{ms}}$ \\
\hline & \multicolumn{6}{|c|}{ Shock } \\
\hline $08 / 98$ & $18.5 \mathrm{~h}$ & $480 \mathrm{~km} / \mathrm{s}$ & 1.8 & 1.8 & $85^{\circ}$ & 1.6 \\
\hline \multirow[t]{3}{*}{$09 / 12$} & $9 \mathrm{~h}$ & $470 \mathrm{~km} / \mathrm{s}$ & 2.1 & 2.3 & $85^{\circ}$ & 2.4 \\
\hline & $P_{\text {dyn }}$ & $B_{z}$ & $M_{\mathrm{ms}}$ & $E_{\mathrm{KL}}$ & $S Y M-H$ & $R_{\mathrm{MP}}$ \\
\hline & \multicolumn{6}{|c|}{ Parameters Before Shock } \\
\hline $08 / 98$ & $2.8 \mathrm{nPa}$ & $-8.5 \mathrm{nT}$ & 5 & $4 \mathrm{mV} / \mathrm{m}$ & $-18 \mathrm{nT}$ & $8.9 R_{E}$ \\
\hline \multirow[t]{2}{*}{$09 / 12$} & $2 \mathrm{nPa}$ & $-6 \mathrm{nT}$ & 4.8 & $2 \mathrm{mV} / \mathrm{m}$ & $-31 \mathrm{nT}$ & $9.8 R_{E}$ \\
\hline & \multicolumn{6}{|c|}{ Parameters After Shock } \\
\hline $08 / 98$ & $8.5 \mathrm{nPa}$ & $-17.5 \mathrm{nT}$ & 4.4 & $10 \mathrm{mV} / \mathrm{m}$ & $-169 \mathrm{nT}$ & $6.1 R_{E}$ \\
\hline $09 / 12$ & $6.8 \mathrm{nPa}$ & $-17 \mathrm{nT}$ & 4.2 & $8 \mathrm{mV} / \mathrm{m}$ & $-111 \mathrm{nT}$ & $6.5 R_{E}$ \\
\hline
\end{tabular}

${ }^{a} S Y M-H a n d$ the subsolar magnetopause distance, $R_{\mathrm{MP}}$, are minimum in the periods considered, the other columns list averages. Dt refers to the CME duration, and $\Delta t$ refers to the time since the start of the magnetic ejecta when the shock is detected. $X_{N}, X_{B}, \Theta$, and $M_{\mathrm{ms}}$ are the density and magnetic compression ratio, the shock angle, and the magnetosonic Mach number.

[Siscoe et al., 2002] and of magnetosphere erosion [Mühlbachler et al., 2005]. However, due to the large dynamic pressure, saturation was not reached for this event. The CPCP measured by DMSP doubled from $\sim 50-60 \mathrm{kV}$ at 6 UT to $100-120 \mathrm{kV}$ at 8 UT, consistent with the doubling of the electric field through the shock. It remained above $100 \mathrm{kV}$ until 13 UT and attained a measured peak of $216 \mathrm{kV}$ in the Southern Hemisphere around 10:30 UT. Overall, the magnetospheric convection was being driven by both dayside $\left(E_{\mathrm{KL}}\right)$ and nightside $(A L)$ sources.

GOES 8 was in the nightside at the time of the shock arrival. The energetic electron flux (above $600 \mathrm{keV}$ ) at geosynchronous orbit experienced a first depression around 2:30 UT followed by a quick recovery (Figure 2b). It decreased again to the lowest flux level due to magnetopause shadowing, starting at 05:00 UT, i.e., in the CME but before the shock arrival (first vertical line) and did not recover until 12:30 UT, i.e., almost coincidentally with the end of the CME (second vertical line).

\section{The 30 September to 1 October 2012 Event}

To put this event in perspective, we discuss briefly the 30 September to 1 October 2012 event (Figure 3). This was another example of a shock inside a CME. It has recently been analyzed by the solar-heliospheric community [Liu et al., 2014], and it drew the attention of the radiation belt community [Baker et al., 2013; Turner et al., 2014; Hudson et al., 2014]. However, to the best of our knowledge, the connection between an unusual shock inside a CME and the large geomagnetic response which wiped out the entire outer radiation belt has not been made. As discussed in Turner et al. [2014], the magnetopause reached geosynchronous orbit for a period of $15 \mathrm{~min}$ starting at 23:50 UT on 30 September about $35 \mathrm{~min}$ after the arrival of the shock. This was due to a combination of moderate dynamic pressure $(\sim 8.2 \mathrm{nPa})$ and large southward $B_{z}(\sim-17 \mathrm{nT})$. Table 1 summarizes selected IP parameters of these two time periods: unless specified, the CME and before values are averaged values for the $3 \mathrm{~h}$ before the shock; the after values are averages over $4 \mathrm{~h}$ for the 1998 event and over $1 \mathrm{~h}$ for the 2012 event.

In many respects, these two time periods were similar: both CMEs were slow, relatively dense, and with weak magnetic fields. The two shocks had similar speed, occurred toward the end of the CME in a period of southward IMF, were quasi-perpendicular, and were relatively weak (but the September 2012 shock was slightly stronger). A main difference in the drivers was the presence of a shock ahead of the September 2012 CME but not ahead of the August 1998 one. This was due to the very slow solar wind speed in September 2012 $\left(\sim 270 \mathrm{~km} \mathrm{~s}^{-1}\right)$, a characteristic of solar cycle 24 [McComas et al., 2013]. This solar wind speed was in the slowest 
$1 \%$ and $5 \%$ of the speed distribution for the solar cycles 23 and 24, respectively [de Toma, 2011]. Another difference was that high dynamic pressure values persisted for a much longer time in the August event, probably due to an ongoing compression from the fast solar wind stream for that event.

The IP parameters relevant to magnetosphere and the geo-effects were also very similar. Before the shock, both CMEs had only a minor effect on the magnetosphere (as measured by SYM- $H$ ). After the shock, an intense geomagnetic storm occurred in both cases, with similar elevated electric fields. The storms were clearly due to the shock and compressed material behind it, as the threshold of SYM-H $=-100 \mathrm{nT}$ was reached within $2 \mathrm{~h}$ of shock impact. In both periods, the magnetopause reached geosynchronous orbit due to the combined large southward magnetic field and elevated dynamic pressure. Both events were associated with significant energetic particle loss in the outer radiation belt. The main difference was that the August 1998 storm was associated with $25 \%$ larger dynamic pressures and a longer forcing for 5.25 instead of $1.75 \mathrm{~h}$. In light of these similarities, we can expect that the extent of the energetic electron loss in the radiation belts on August 1998 was at least comparable to that measured by Van Allen Probes on 30 September 2012.

\section{Discussion and Conclusion}

CMEs are often associated with two sequential effects, reflected in two-dip storms [Kamide et al., 1998]: the driven shock and the magnetic ejecta. Here we have presented two cases where the two sequential effects were combined into one, resulting in an intense geomagnetic disturbance for a relatively weak driver. This type of driver combines characteristics of CMEs (steady, elevated $B_{z}$ ) and shocks (jump of the dynamic pressure).

For the 6 August 1998, we have shown how the effects of the shock inside a CME and of the compressed CME region just downstream of the shock dwarfed the individual effects of the CME and the shock. Although both the shock and the CME were weak, the magnetopause reached geosynchronous orbit for several hours. This occurred because of the simultaneous jump in dynamic pressure and southward $B_{z}$, the latter eroding the dayside magnetosphere. GOES 8 measured a large drop of the flux of energetic electrons at geosynchronous orbit which stopped with the end of the compressed CME, consistent with magnetopause shadowing [Yu et al., 2013].

The 30 September 2012 shock was another case of a very geo-effective shock within a CME [Liu et al., 2014]. Van Allen Probes measurements of the radiation belt revealed how the shock caused a large decrease in the flux of energetic particles in the outer radiation belt [Turner et al., 2014]. Many of the CME and shock characteristics, as well as the IP conditions before and after the shock in 30 September 2012, were highly reminiscent of the August 1998 event, including the elevated dynamic pressure and southward $B_{z}$ directly after the shock. These examples illustrate how the origin of shocks and the IP medium into which they propagate should be carefully analyzed in order to understand their geomagnetic impact.

Acknowledgments

We would like to thank the reviewers for their useful comments which helped us to improve the manuscript. We are grateful to Lan Jian for helpful discussions. The research for this manuscript was supported by the following grants: NSF AGS-1239699, NASA NNX13AP39G, NNX13AH94G, NNX15AB87G, and RBSP-ECT funding provided by JHU/APL contract 967399 under NASA's Prime contract NAS5-01072. We acknowledge the use of the NASA/GSFC OMNIWEB and CDAWEB data to obtain the Wind, Geotail, and GOES data.

The Editor thanks Michael Denton and an anonymous reviewer for their assistance in evaluating this paper.

\section{References}

Baker, D. N., et al. (2013), A long-lived relativistic electron storage ring embedded in Earth's outer Van Allen Belt, Science, 340, 186-190, doi:10.1126/science.1233518.

Borovsky, J. E., and M. H. Denton (2006), Differences between CME-driven storms and CIR-driven storms, J. Geophys. Res., 111, A07S08, doi:10.1029/2005JA011447.

de Toma, G. (2011), Evolution of coronal holes and implications for high-speed solar wind during the minimum between cycles 23 and 24 , Sol. Phys., 274, $195-217$.

Farrugia, C. J., N. V. Erkaev, H. K. Biernat, and L. F. Burlaga (1995), Anomalous magnetosheath properties during Earth passage of an interplanetary magnetic cloud, J. Geophys. Res., 100, 19,245-19,258, doi:10.1029/95JA01080.

Gosling, J. T., D. J. McComas, J. L. Phillips, and S. J. Bame (1991), Geomagnetic activity associated with earth passage of interplanetary shock disturbances and coronal mass ejections, J. Geophys. Res., 96, 7831-7839, doi:10.1029/91JA00316.

Grib, S. A., B. E. Briunelli, M. Dryer, and W. -W. Shen (1979), Interaction of interplanetary shock waves with the bow shock-magnetopause system, J. Geophys. Res., 84, 5907-5921, doi:10.1029/JA084iA10p05907.

Hudson, M. K., D. N. Baker, J. Goldstein, B. T. Kress, J. Paral, F. R. Toffoletto, and M. Wiltberger (2014), Simulated magnetopause losses and Van Allen Probe flux dropouts, Geophys. Res. Lett., 41, 1113-1118, doi:10.1002/2014GL059222.

Jian, L., C. T. Russell, J. G. Luhmann, and R. M. Skoug (2006), Properties of stream interactions at one AU during 1995-2004, Sol. Phys., 239, 337-392, doi:10.1007/s11207-006-0132-3.

Kamide, Y., N. Yokoyama, W. Gonzalez, B. T. Tsurutani, I. A. Daglis, A. Brekke, and S. Masuda (1998), Two-step development of geomagnetic storms, J. Geophys. Res., 103, 6917-6922, doi:10.1029/97JA03337.

Kan, J. R., and L. C. Lee (1979), Energy coupling function and solar wind-magnetosphere dynamo, Geophys. Res. Lett., 6, 577-580, doi:10.1029/GL006i007p00577.

Lavraud, B., and J. E. Borovsky (2008), Altered solar wind-magnetosphere interaction at low Mach numbers: Coronal mass ejections, J. Geophys. Res., 113, A00B08, doi:10.1029/2008JA013192. 
Liu, Y. D., Z. Yang, R. Wang, J. G. Luhmann, J. D. Richardson, and N. Lugaz (2014), Sun-to-Earth characteristics of two coronal mass ejections interacting near $1 \mathrm{AU}$ : Formation of a complex ejecta and generation of a two-step geomagnetic storm, Astrophys. J. Lett., $793,41$.

Lugaz, N., C. J. Farrugia, C. W. Smith, and K. Paulson (2015), Shocks inside CMEs: A survey of properties from 1997 to 2006, J. Geophys. Res. Space Physics, 120, 2409-2427, doi:10.1002/2014JA020848.

McComas, D. J., N. Angold, H. A. Elliott, G. Livadiotis, N. A. Schwadron, R. M. Skoug, and C. W. Smith (2013), Weakest solar wind of the space age and the current "Mini" solar maximum, Astrophys. J., 779, 2, doi:10.1088/0004-637X/779/1/2.

Mühlbachler, S., C. J. Farrugia, J. Raeder, H. K. Biernat, and R. B. Torbert (2005), A statistical investigation of dayside magnetosphere erosion showing saturation of response, J. Geophys. Res., 110, A11207, doi:10.1029/2005JA011177.

Panov, E. V., J. Büchner, M. Fränz, A. Korth, S. P. Savin, H. Rème, and K. -H. Fornaçon (2008), High-latitude Earth's magnetopause outside the cusp: Cluster observations, J. Geophys. Res., 113, A01220, doi:10.1029/2006JA012123.

Richardson, I. G., and H. V. Cane (2010), Near-Earth interplanetary coronal mass ejections during solar cycle 23 (1996-2009): Catalog and summary of properties, Sol. Phys., 264, 189-237, doi:10.1007/s11207-010-9568-6.

Richardson, I. G., E. W. Cliver, and H. V. Cane (2001), Sources of geomagnetic storms for solar minimum and maximum conditions during 1972-2000, Geophys. Res. Lett., 28, 2569-2572, doi:10.1029/2001GL013052.

Samsonov, A. A., Z. Němeček, and J. Šafránková (2006), Numerical MHD modeling of propagation of interplanetary shock through the magnetosheath, J. Geophys. Res., 111, A08210, doi:10.1029/2005JA011537.

Shue, J.-H., et al. (1998), Magnetopause location under extreme solar wind conditions, J. Geophys. Res., 103, 17,691-17,700, doi:10.1029/98JA01103.

Siscoe, G. L., N. U. Crooker, and K. D. Siebert (2002), Transpolar potential saturation: Roles of region 1 current system and solar wind ram pressure, J. Geophys. Res., 107(A10), 1321, doi:10.1029/2001JA009176.

Turner, D. L., et al. (2014), On the cause and extent of outer radiation belt losses during the 30 September 2012 dropout event, J. Geophys. Res. Space Physics, 119, 1530-1540, doi:10.1002/2013JA019446.

Wang, Y. M., P. Z. Ye, S. Wang, and X. H. Xue (2003), An interplanetary cause of large geomagnetic storms: Fast forward shock overtaking preceding magnetic cloud, Geophys. Res. Lett., 30(13), 1700, doi:10.1029/2002GL016861.

Yu, Y., J. Koller, and S. K. Morley (2013), Quantifying the effect of magnetopause shadowing on electron radiation belt dropouts, Ann. Geophys., 31, 1929-1939, doi:10.5194/angeo-31-1929-2013.

Zhang, J., et al. (2007), Solar and interplanetary sources of major geomagnetic storms (Dst < -100 nT) during 1996-2005, J. Geophys. Res., 112, A10102, doi:10.1029/2007JA012321. 